\title{
Prediction of nitrate concentration from two end member mixing in the southern East China Sea
}

\author{
GWO-CHING GONG, ${ }^{*}$ KON-KEE LIU† and SU-CHENG PAI $\dagger$
}

(Received 1 June 1993; accepted 14 January 1994)

\begin{abstract}
Monthly hydrographic surveys were conducted along two transects across the Kuroshio frontal zone in the southern East China Sea from August 1990 to July 1991. The concentration of nitrate in the shelf water was linearly related to temperature. However, the relationship varied with time. This relationship could have resulted from two end member mixing between the nitratedevoid surface water and the nitrate-laden upwelled water. While the temperature of surface water was temporally variable, the temperature-nitrate properties of the upwelled water were almost invariant. The temperature of the surface end member $\left(T_{s}\right)$ correlated well with the mean air temperature $\left(T_{a}\right)$ at a weather station in the study area according to the equation: $T_{s}=15.3+0.45$ $\times T_{a}$. The upwelled water, which was brought to the shelf by bottom intrusion of the Kuroshio, had properties similar to those of the Kuroshio subsurface water at $\sigma_{\theta}=25.8$ with a mean temperature of $14.8^{\circ} \mathrm{C}$ and a nitrate concentration of $13.2 \mu \mathrm{M}$. With the exception of the data obtained in September 1990, the concentration of nitrate in the shelf water can be predicted from the mean air temperature with a mean error of $0.9 \mu \mathrm{M}$ from the observed values. The anomaly observed in September 1990 might have been the result of the unsteady condition during the reversal of the direction of the monsoon. There was also a slight deviation from the predicted trend in March 1991 when there was a seaward excursion of the Continent Coastal Water which may have constituted a third end member in the mixing process. In general, this simple mixing model is applicable to the middle and outer shelf north of Taiwan.
\end{abstract}

\section{INTRODUCTION}

Because the primary productivity in the marginal seas could be as important as that in the ocean interior (Walsh, 1991), increasing attention has been given to understand the oceanography of these seas (JGOFS, 1992). A dome of cold water, which resulted from an upwelling, or a bottom intrusion, of the subsurface Kuroshio water, has frequently been observed at the shelf break off the northern tip of Taiwan (Chern and Wang, 1990; Liu et al., 1992a). This dome has been shown to persist throughout the year (Liu et al., 1992b) and it is potentially a major source of nutrients to the East China Sea (Wong et al., 1991). The East China Sea is one of the largest marginal seas in the world. The southern East China Sea (SECS) to the north of Taiwan has high concentrations of chlorophyll $a$ (Chen, 1992) and a high density of ichthyoplankton (Chiu, 1991) and it is one of the most important fishing grounds near Taiwan (Anon, 1990).

\footnotetext{
*Department of Oceanography, National Taiwan Ocean University, Keelung, Taiwan, Republic of China.

†Institute of Oceanography, National Taiwan University, Taipei, Taiwan, Republic of China.

$\ddagger$ Global Change Research Center, National Taiwan University, Taipei, Republic of China.
} 


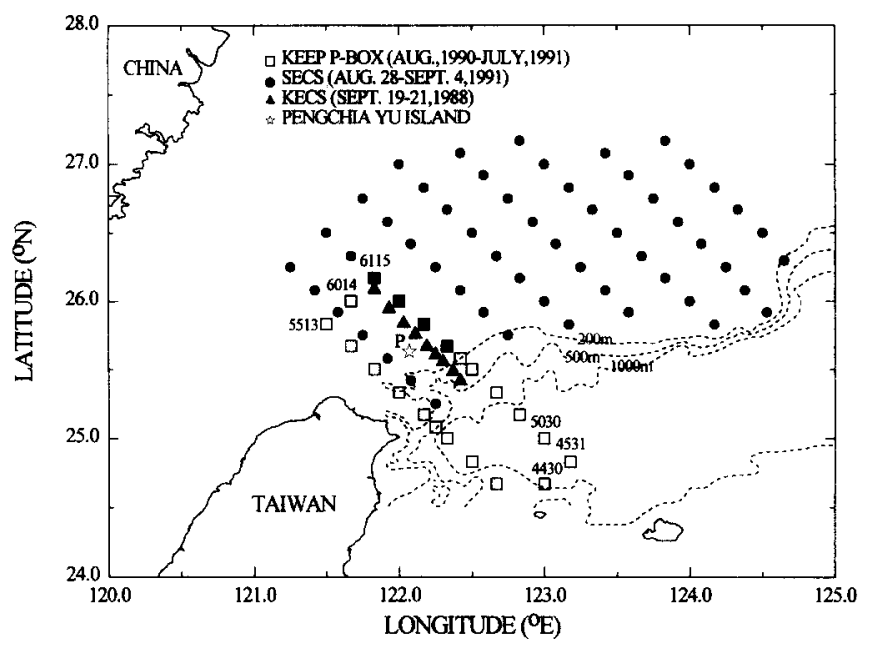

Fig. 1. Sampling stations for chemical hydrography studies. Different symbols represent stations occupied on different cruises. Dashed curves represent the bottom contours of 200,500 and 1000 $\mathrm{m}$. The hollow star indicates the Pengchia Yu weather station.

An important factor in the algorithm for a synoptic assessment of new production by means of remotely sensed ocean color is to determine the nitrate concentration in the euphotic zone (e.g. Dugdale et al., 1989; Sathyendranath et al., 1991). One of the approaches is to predict the nitrate concentration from the satellite sea surface temperature $(S S T)$ if the relationship between temperature and nitrate is known. In addition, such a relationship is also a key factor for estimating the nutrient fluxes during shelfward intrusion of the western boundary current (e.g. Atkinson, 1985). A linear temperaturenitrate relationship is known in other upwelling areas (e.g. Brink et al., 1981; Jones et al., 1983). In the SECS monthly hydrographic surveys had been conducted along two transects off northern Taiwan. These surveys revealed the persistency of the upwelling (Liu et al., 1992b) which provides a constant supply of nutrients to the shelf. They have also demonstrated that a linear relationship between temperature and nitrate existed throughout the year although the relationship varied seasonally. In another survey of the entire mid- and outer shelf of the SECS, the aforementioned linear relationship was shown to be valid in a much wider area. In this study, a simple mixing model is established to formulate the temperature-nitrate relationship from the 7-day running mean of the air temperature in the SECS.

\section{MATERIALS AND METHODS}

This study. was a part of the multidisciplinary KEEP (Kuroshio Edge Exchange Processes) project. We undertook monthly cruises on board the R.V. Ocean Researcher I from August 1990 to July 1991, except in February 1991 when the vessel was under annual inspection and maintenance. The 11 cruises for chemical hydrographic survey were along two transects, which were dubbed as the P-Box, off northern Taiwan (Fig. 1). The cruise information is listed in Table 1. During the period of 28 August-4 September 1991, a cruise was conducted to survey 86 stations in the SECS (Fig. 1). 
Table 1. Information of cruises for chemical hydrographic survey in the southern East China Sea study area

\begin{tabular}{lcccc}
\hline Cruise name & $\begin{array}{c}\text { Cruise } \\
\text { No. }\end{array}$ & Date $(\mathrm{mm} / \mathrm{dd} / \mathrm{yy})$ & $\begin{array}{c}\text { No. of stations } \\
\text { occupied }\end{array}$ & $\begin{array}{c}\text { No. of stations } \\
\text { on the shelf }\end{array}$ \\
\hline KEEP & 248 & $08 / 01-06 / 90$ & 21 & 10 \\
& 254 & $09 / 18-23 / 90$ & 21 & 10 \\
& 258 & $10 / 20-25 / 90$ & 21 & 10 \\
& 260 & $11 / 03-07 / 90$ & 21 & 10 \\
& 264 & $12 / 03-06 / 90$ & 10 & 3 \\
& 268 & $01 / 12-15 / 91$ & 18 & 8 \\
& 271 & $03 / 04-09 / 91$ & 21 & 10 \\
& 275 & $04 / 01-06 / 91$ & 21 & 10 \\
& 280 & $05 / 02-07 / 91$ & 17 & 10 \\
& 285 & $06 / 07-12 / 91$ & 21 & 3 \\
SECS & 288 & $07 / 15-18 / 91$ & 12 & 4 \\
KECS & 289 & $07 / 22-23 / 91$ & 10 & 59 \\
& 293 & $08 / 28-09 / 04 / 91$ & 86 & 9 \\
\hline
\end{tabular}

A Seabird CTD-General Oceanic Rosette assembly with 11 Niskin bottles was used to obtain temperature and salinity profiles and seawater samples. Water samples for the determination of nitrate were collected from the water samplers with 100 -ml polypropylene bottles and were frozen instantly with liquid nitrogen and stored in a freezer. The frozen samples were thawed under running tap water in the home-laboratory and the concentration of nitrate in these samples were determined immediately after thawing. During the August-September 1991 cruise, all of the samples were analyzed for nitrate onboard ship within $12 \mathrm{~h}$ after sampling. Nitrate was analyzed with a flow injection analyzer. It was reduced to nitrite with a cadmium wire which was activated with a copper sulfate solution (Strickland and Parsons, 1972; Gardner et al., 1976), and the nitrate was converted to the pink azo dye for colorimetric determination (Morris and Riley, 1963; Pai et al., 1990). The precision for the analysis was $\pm 0.3 \mu \mathrm{M}$ for concentrations of $10 \mu \mathrm{M}$ or higher. Daily air temperature data were obtained from the Central Weather Bureau weather station, which is located at an altitude of $102 \mathrm{~m}$, on an offshore islet, Pengchia $\mathrm{Yu}$, within the study area (Fig. 1) and the 7-day running mean temperature was estimated from these data.

\section{RESULTS AND DISCUSSION}

The temperature-nutrient relationship for the shelf water in our study area is distinct from that for the Okinawa Trough. The relationship for the latter area is curvilinear and shows very little seasonal change (Wong et al., 1991; Liu et al., 1992a; Gong, 1992), whereas the relationship in our study area is almost linear (Liu et al., 1988, 1992a). Here we present observations of the temperature-nitrate relationship for the shelf water at stations with depths of less than $200 \mathrm{~m}$ in the SECS during an entire annual cycle.

\section{Linear relationship of nitrate concentration and temperature}

The concentration of nitrate $\left(\mathrm{NO}_{3}\right)$ was plotted against temperature $(\Theta)$ for each cruise (Fig. 2). In general, it varied linearly with temperature throughout the year but the 


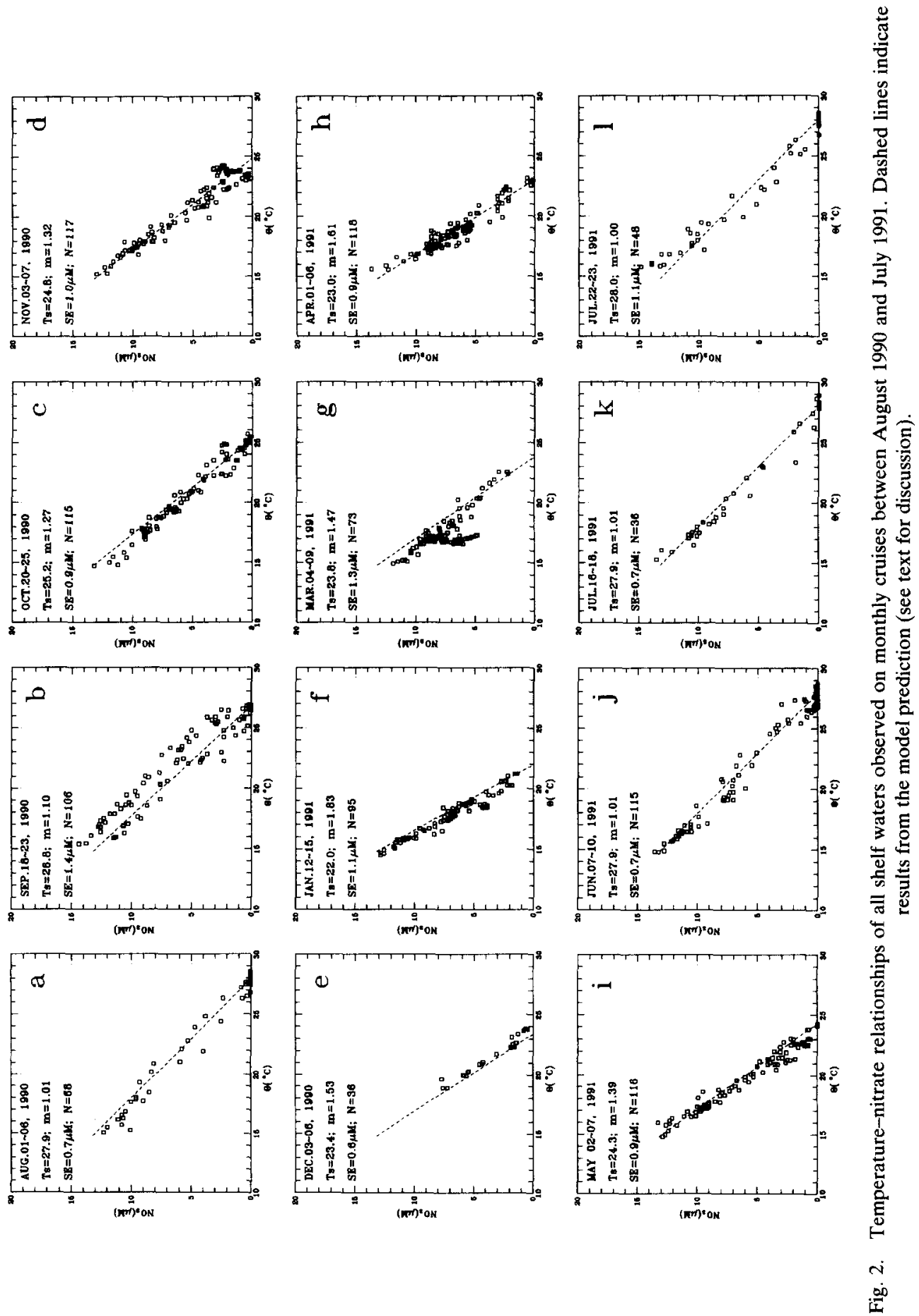


Table 2. Results from linear regression analysis of nitrate concentration against temperature for repeated hydrographic surveys along $P$-Box

\begin{tabular}{lccccrc}
\hline Date & Slope & $\begin{array}{c}x \text {-intercept } \\
\left({ }^{\circ} \mathrm{C}\right)\end{array}$ & $\begin{array}{c}y \text {-intercept } \\
(\mu \mathrm{M})\end{array}$ & $R^{2}$ & $N \div$ & $\begin{array}{c}\text { S.E. } \\
(\mu \mathrm{M})\end{array}$ \\
\hline $08 / 01-06 / 90$ & -0.92 & 28.1 & 25.85 & 0.98 & 68 & 0.6 \\
$09 / 18-23 / 90$ & -1.17 & 27.0 & 31.60 & 0.94 & 106 & 1.2 \\
$10 / 20-25 / 90$ & -1.11 & 25.5 & 28.26 & 0.96 & 115 & 0.7 \\
$11 / 03-07 / 90$ & -1.31 & 24.6 & 32.25 & 0.92 & 117 & 1.0 \\
$12 / 03-06 / 90$ & -1.45 & 24.0 & 34.74 & 0.95 & 36 & 0.5 \\
$01 / 12-15 / 91$ & -1.78 & 21.7 & 38.55 & 0.94 & 95 & 0.8 \\
$03 / 04-09 / 91^{*}$ & -1.16 & 24.5 & 28.39 & 0.94 & 73 & 0.5 \\
$04 / 01-06 / 91$ & -1.48 & 23.2 & 34.33 & 0.92 & 118 & 0.8 \\
$05 / 02-07 / 91$ & -1.50 & 23.7 & 35.53 & 0.97 & 116 & 0.7 \\
$06 / 07-12 / 91$ & -0.97 & 27.9 & 27.06 & 0.98 & 115 & 0.7 \\
$07 / 15-18 / 91$ & -0.98 & 28.0 & 27.39 & 0.97 & 36 & 0.8 \\
$07 / 22-23 / 91$ & -1.09 & 27.7 & 30.19 & 0.97 & 48 & 1.0 \\
\hline
\end{tabular}

*Samples with salinity below 34.0 psu are excluded for regression. †Number of samples.

$\ddagger$ Standard error of the estimate.

relationship was different from cruise to cruise. Results from linear regression analysis are listed in Table 2. The average correlation coefficient $\left(R^{2}\right)$ is 0.95 . The standard errors of the estimate (S.E.) between the observed and the estimated from the regression lines were all less then $1 \mu \mathrm{M}$ except for the cruise of September $1990(\mathrm{~S} . \mathrm{E} .=1.2 \mu \mathrm{M})$. It is noted that for the March 1991 cruise, only those samples with salinity above 34.0 psu were used for regression analysis. We will discuss this matter later.

Although nitrate is not a conservative tracer, it appeared to behave conservatively as a result of mixing between two end members (Fig. 2). Such a behavior is apparently related to the rapid mixing processes on the shelf by strong internal motion (Chern and Wang, 1990). Hence, the linearity between $\mathrm{NO}_{3}$ and $\Theta$ was assumed to result from two end member mixing. One end member is a warm surface water devoid of nitrate, and the other is the nitrate laden upwelled cold Kuroshio subsurface water.

The surface end member, which is defined as the $x$-intercept of the $\Theta-\mathrm{NO}_{3}$ regression line (Table 2), had variable temperature and concentration of nitrate. The temperature is subjected to the seasonal changes. The three most landward stations of the P-Box (namely, Stas 5513, 6014 and 6115) are used to represent the shelf water and the three deepest stations (namely 4430, 4531 and 5030) are used to represent the deep sea where the Kuroshio flows. The annual variation of the temperature of the surface end member $\left(T_{s}\right)$, the 7-day running mean air temperature $\left(T_{a}\right)$ at Pengchia $Y \mathbf{u}$, the sea surface temperatures in the shelf waters and at the deep stations all shown in Fig. 3. The surface temperature of the shelf water followed the variations of the air temperature most closely. The surface temperature at the deep stations showed only slight cooling in winter and spring, as a result of the influence of the Kuroshio (Fig. 3). $T_{s}$ resembled the surface temperature of the shelf water from June to October, but fell between those of the shelf sea and the deep sea. In fact, the surface end member was quite similar to the Kuroshio surface water in winter when the Kuroshio intrusion onto the shelf occurs (Sun, 1987; Chao, 1991). In January and March, 1991, the surface waters on the shelf were all laden with nutrient. Therefore, the 


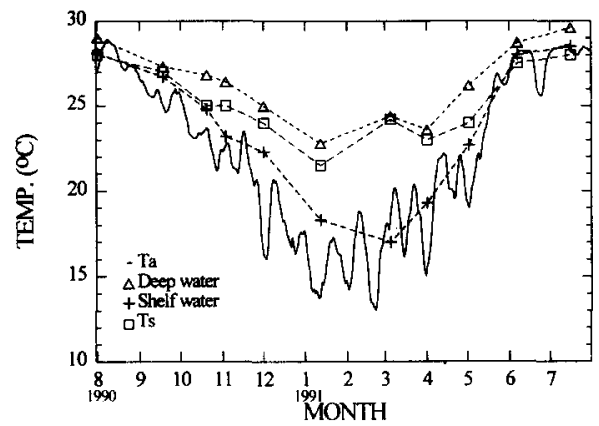

Fig. 3. Variation of temperature of the surface end member (squares), the sea surface temperatures in the deep (triangles) and the shelf (crosses) region. The solid line indicated the 7-day running mean air temperature at Pengchia Yu Island.

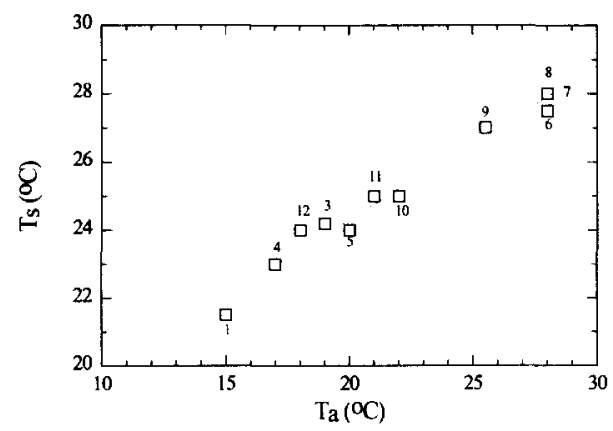

Fig. 4. Correlation between the temperature of the surface end member $\left(T_{s}\right)$ and the 7-day running mean air temperature $\left(T_{a}\right)$ at Pengchia Yu.

surface end member was not found on the shelf but located slightly more seaward from the shelf break. The mixing might be facilitated by tidal motion, and frontal eddies (Lin et al., 1992a).

Although $T_{s}$ was considerably higher than $T_{a}$ in winter and spring, a good correlation was found between them (Fig. 4). Hence, $T_{s}$ may be calculated from the following equation for a known $T_{a}$ :

$$
T_{s}=15.3+0.45 \times T_{a} R^{2}=0.97 .
$$

The upwelled Kuroshio subsurface water has been shown to be an important end member in the shelf water on several occasions (e.g. Chern and Wang, 1989; Wong et al., 1991; Liu et al., 1992a). Here we demonstrate that such an end member existed in the shelf water throughout the year. The $\Theta-S$ diagrams of the monthly cruises (Fig. 5) show that, despite very diverse water properties on the shelf, they all converged at $\sigma_{\theta}$ of 25.8 with temperature around $15^{\circ} \mathrm{C}$ and salinity of $34.6 \mathrm{psu}$. The bottom water at this density level on the shelf had a mean temperature of $14.8 \pm 0.4^{\circ} \mathrm{C}$, a mean salinity of $34.58 \pm 0.03 \mathrm{psu}$ and a mean nitrate concentration of $13.2 \pm 0.9 \mu \mathrm{M}$. Such water can be identified as a Kuroshio subsurface water. 


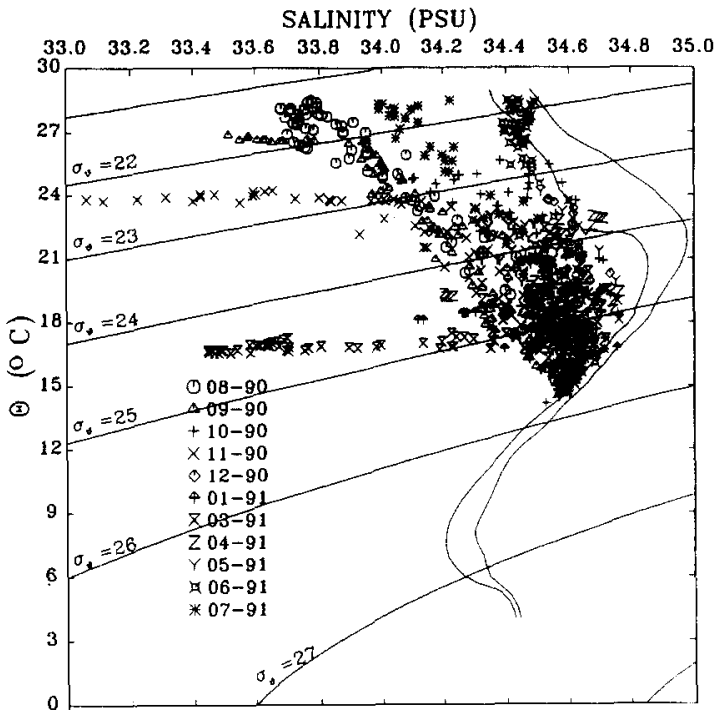

Fig. 5. The $\Theta-S$ relationships of shelf water observed on the KEEP cruises. Different symbols represent different cruises. Solid curves represent the mean $\Theta-S$ characteristics of the Kuroshio.

\section{Prediction of nitrate concentration from the two end member mixing}

The linear relationship between nitrate and temperature can be formulated as the following equation:

$$
N_{w}=N_{b}-m \times\left(T_{w}-T_{b}\right)
$$

where $N_{w}=$ nitrate concentration in seawater, $N_{b}=$ nitrate concentration in bottom water (= 13.2 $\pm 0.9 \mu \mathrm{M}), T_{w}=$ temperature of seawater, $T_{b}=$ temperature of bottom water $\left(=14.8 \pm 0.4^{\circ} \mathrm{C}\right), m=N_{b} /\left(T_{s}-T_{b}\right)$.

This equation has only one variable because the two end members have constant properties, except $T_{s}$ which can be determined from the mean air temperature by equation (1).

The derived $\Theta-\mathrm{NO}_{3}$ relationship from equation (2) for each month is compared with that from field observations (Fig. 2). The agreement is quite good. The standard error of the estimate (S.E.) between the observed and the predicted values of nitrate concentration varied from 0.6 to $1.4 \mu \mathrm{M}$ in the different months with an overall mean of $1.0 \mu \mathrm{M}$. However, such a scheme of prediction cannot be applied to waters of very low salinity in winter and in spring as observed in March 1991.

During the cruise of March 1991, some of the water samples from the most landward stations showed a trend of negative nitrate anomaly around the temperature of $17^{\circ} \mathrm{C}$ [Fig. 2(g)]. Hydrographic conditions along these two transects (Fig. 6) are invoked to explain such an anomaly. Waters of very low salinity ( $<34.0 \mathrm{psu})$ appeared at the innermost stations on the shelf and pressed against the saline Kuroshio water near the shelf break. The low salinity shelf water which was enriched in nitrate and saturated in oxygen probably contained a large fraction of Continent Coastal Water (CCW) (Miao and Yu, 1990; Liu et $a l ., 1992 \mathrm{~b}$ ). This water, which is readily detectable by hydrographic survey, is distinct from the previous two end members. It is even possible to detect this water by satellite remote 


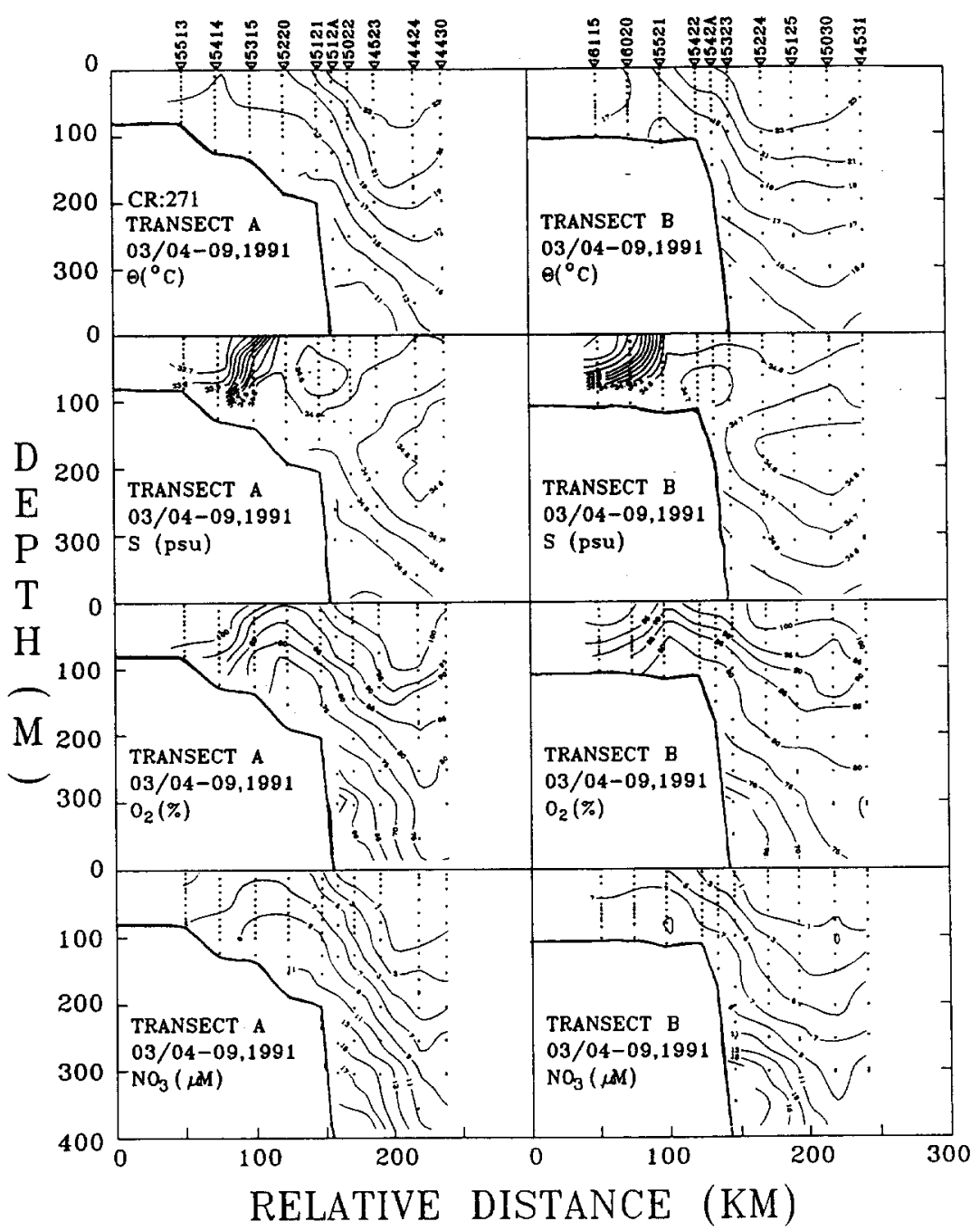

Fig. 6. The section contours of temperature $(\Theta)$, salinity $(S)$, degree of oxygen saturation $\left(\mathrm{O}_{2} \%\right)$ and nitrate $\left(\mathrm{NO}_{3}\right)$ sections along KEEP transects (A and $\left.\mathrm{B}\right)$ during 4-9 March 1991. Transect $\mathrm{A}$ is the one closer to Taiwan.

sensing because it stays in the top layer and contains a high concentration of total suspended matter, $1 \sim 4 \mathrm{mg} \mathrm{l}^{-1}$ (Gong, unpublished data).

The $\Theta-S$ diagram (Fig. 5) also showed the marked mixing trend caused by the CCW which has rather narrow temperature range and a very large salinity range. Although such seaward excursion of the CCW also occurred in other months, e.g. November 1990, a relatively small anomaly in the $\Theta$-nitrate relationship was observed [Fig. 2(d)]. Because the CCW had little nitrate and its temperature was similar to the surface end member on the other occasions, it was almost indistinguishable from the normal surface end member.

The deviations between the observed and the predicted nitrate concentration for September 1990 were the highest. In many water samples, the observed concentration of nitrate was higher than that predicted from the $\Theta-\mathrm{NO}_{3}$ trend [Fig. 2(b)]. This cruise was 
undertaken shortly after the reversal of the prevailing wind (Liu et al., 1992a). An abrupt intensification of upwelling occurred during the cruise as indicated by the serial satellite $S S T$ imagery. The bottom water at the shelf break showed slightly lower temperature and higher nitrate concentration in September than the adjacent months (Liu et al., 1992a), suggesting that the strong upwelling probably bought slightly deeper water to the shelf. At the same time, a low salinity warm filament existed in juxtaposition against the upwelled water. Such arrangement of the water masses might result in a mixing trend different from the more steady condition.

\section{Applicability of the mixing model in other time and space}

A historical data set taken from a cruise during 19-21 September 1988 (Wong et al., 1989) was used to test the applicability of our mixing model in a different year. There were nine stations occupied on the shelf (solid triangle in Fig. 1) during this cruise. Wong et al. (1991) indicated that nitrate concentration varied linearly with temperature. The mean air temperature at Pengchia $\mathrm{Yu}$ weather station was $27.0^{\circ} \mathrm{C}$. The temperature of the surface end member was calculated to be $27.5^{\circ} \mathrm{C}$ from equation (1). Then, nitrate concentration can be estimated from the following equation:

$$
N_{w}=13.2-1.04 \times\left(T_{w}-14.8\right) .
$$

The prediction fits the observation quite well. The standard error of the estimate was 1.0 $\mu \mathrm{M}$, which is mostly attributed to scattering of the data.

In order to test the spatial applicability of the mixing model, the hydrographic data from the 59 stations on the SECS shelf (Fig. 1) obtained on the cruise in August-September 1991 were examined. The mean air temperature $\left(T_{a}\right)$ during this cruise was about $28.0^{\circ} \mathrm{C}$ at the Pengchia Yu weather station. The end member of the sea surface temperature $\left(T_{s}\right)$ obtained from equation (1) was $27.9^{\circ} \mathrm{C}$. By substituting $T_{s}$ into equation (2), nitrate concentration can be estimated by the following equation:

$$
N_{w}=13.2-1.00 \times\left(T_{w}-14.8\right) .
$$

The $\Theta-\mathrm{NO}_{3}$ plot for the samples from the five transects to the southwest show scattering on both sides of the predicted line with a standard error of the estimate of $1.0 \mu \mathrm{M}$ [Fig. 7(a)]. On the other hand, almost all data from the three transects to the northeast fall below the predicted line.

Figure 7(b) shows that the $\Theta-S$ relationships along the cross-shelf transects converged at $\sigma_{\theta}=25.8$ density level, except for the three northeastern transects. For this latter group, the $\Theta-S$ relationship converged at a less dense isopycnal $\left(\sigma_{\theta}=25.2\right)$. This indicates that the common bottom end member existed in an area of about $200 \mathrm{~km} \times 200 \mathrm{~km}$ in the midand outer shelf north of Taiwan. To the north of this area, the temperature of the bottom end member became higher, corresponding to a lower nitrate concentration. In addition, the surface end member became cooler than predicted. In fact, the satellite SST imagery showed a gradual cooling trend towards the north. Nevertheless, the linearity of the $\Theta-\mathrm{NO}_{3}$ relationship was still quite good, and the bottom end member also originated from the Kuroshio subsurface water, but from a shallower depth. In order to expand the applicability of our simple two-end-member mixing model, the spatial change in properties of the end members should be parameterized, which warrants further investigation along the shelf of the East China Sea. 

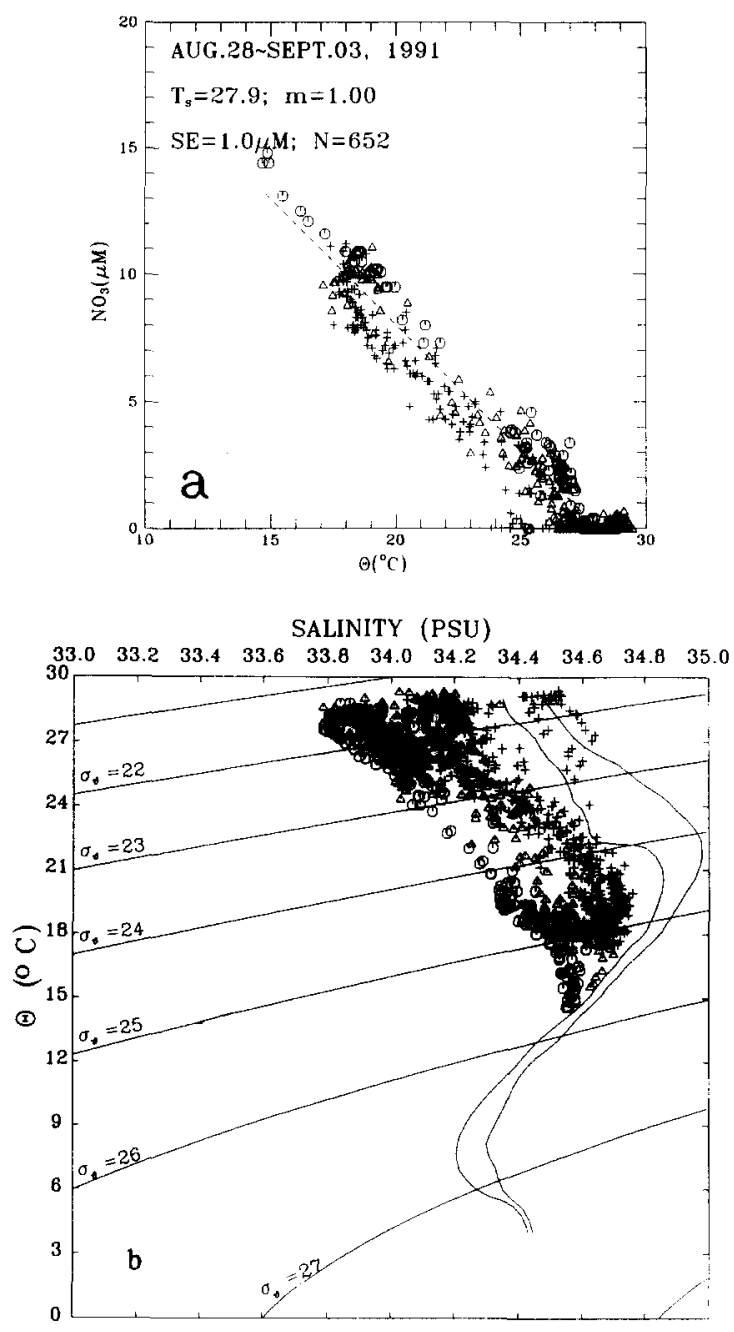

Fig. 7. (a) The comparison between the predicted temperature-nitrate relationship (dashed line) and observations in the shelf water on the SECS cruise (28 August 1991). Circles represent samples from the first two cross-shelf transects closest to Taiwan. Triangles represent those from the next three transects. Crosses represent those of the three farthest transects. (b) The $\Theta-S$ relationships of shelf water observed on the SECS cruise. Solid curves represent the mean $\Theta-S$ characteristics of the Kuroshio. The symbols are the same as those in Fig. 7(a).

\section{Determination of nitrate distribution in surface water from satellite SST}

Because of the limited coverage of an oceanographic expedition, it often fails to grasp very important features of oceanic conditions. For example, we could not depict the areal distribution of nutrients in the surface water under the influence of upwelling off northern Taiwan by our cruises along the P-Box. Using the scheme of nitrate prediction, we could convert the satellite imagery of SST into a nitrate distribution pattern.

Such application is demonstrated with the case study of July 1991 . On the hydrographic cruise which was interrupted by a typhoon, only the southern transect of the P-Box was 


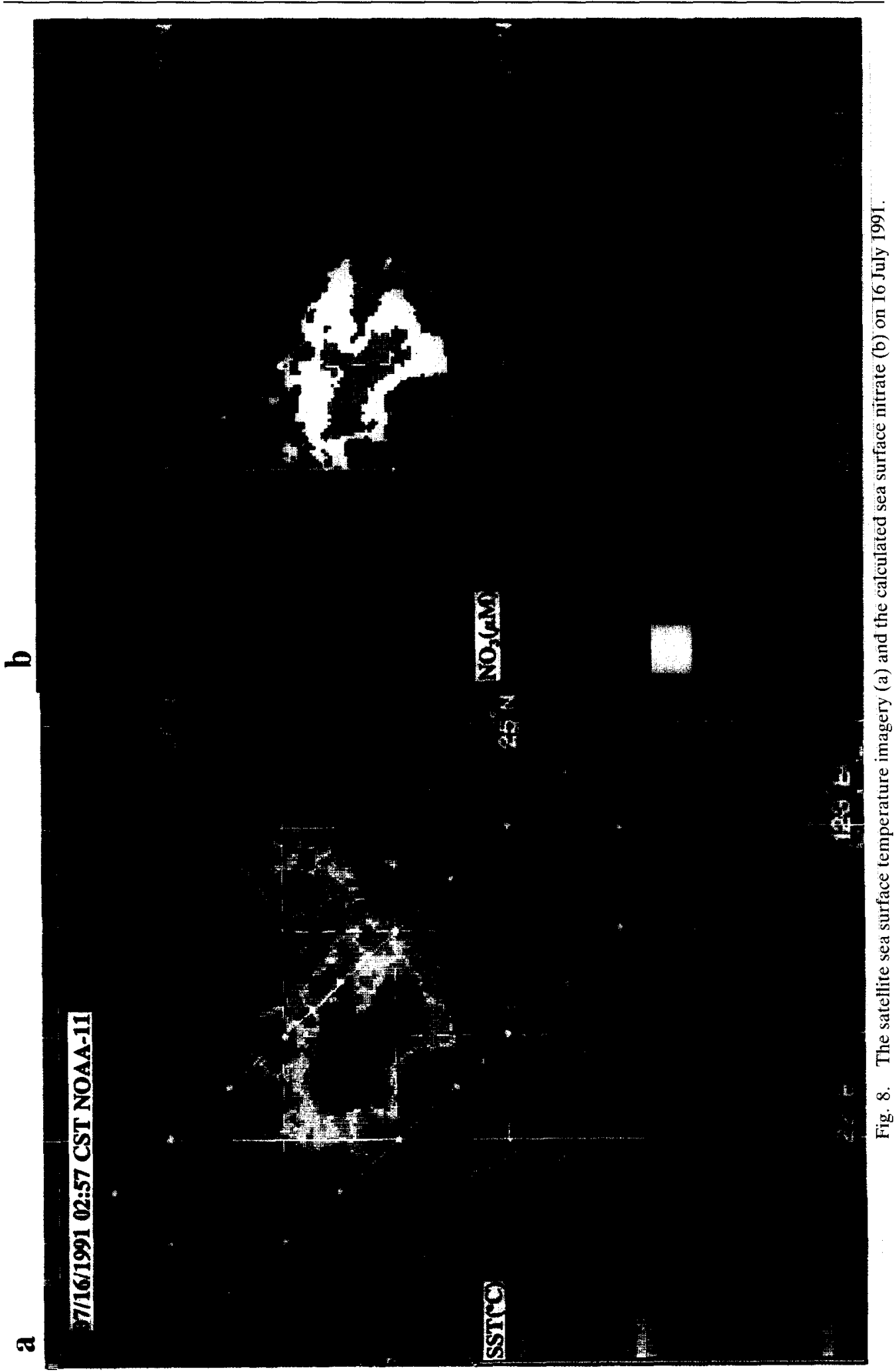




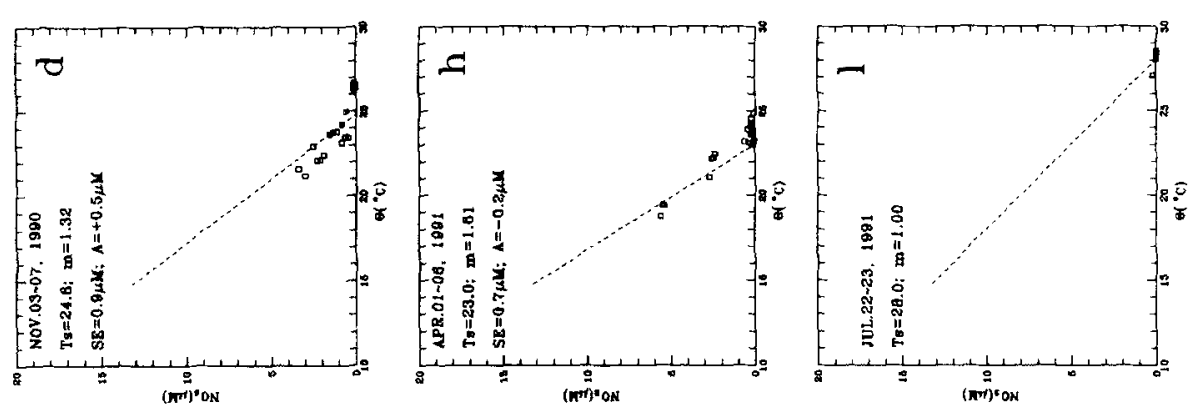

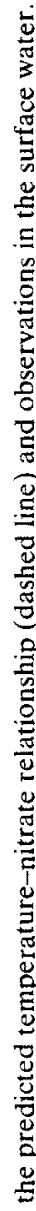
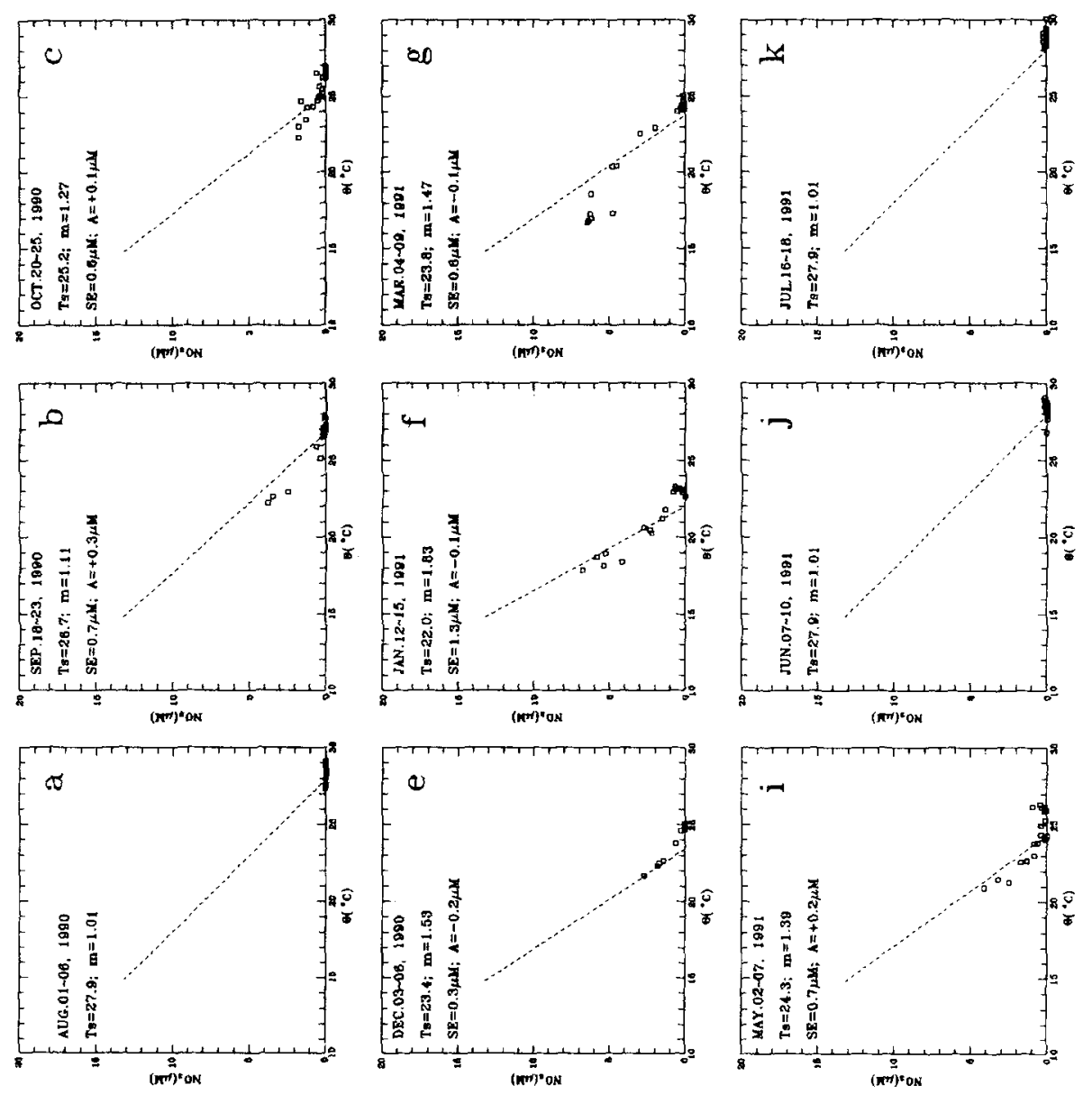

造 
completely surveyed. No nutrient was found in the surface water. However, the satellite SST map [Fig. 8(a)] indicates that an upwelling condition was well developed. The nitrate distribution map [Fig. 8(b)], which was produced from the $\Theta-\mathrm{NO}_{3}$ relationship, showed a maximum nitrate concentration as high as $4 \mu \mathrm{M}$ in the center of the upwelling area. The area of the surface water with detectable nitrate concentration could be greater than 5000 $\mathrm{km}^{2}$.

In our simple mixing model, utilization of nitrate is not considered but it could be very important in the surface water and result in significant error. Therefore, we compared the predicted and the observed values for the surface water at all stations of the P-Box (Fig. 9). The $x$-intercept is clearly the threshold temperature, above which little nitrate is present. The hydrographic survey did not find any nitrate-containing water at the surface on the cruises from June to August. For the other months, the data allow a comparison, which yields an averaged standard error of estimate of $0.7 \mu \mathrm{M}$, which may be regarded as the precision of nitrate prediction for the surface water.

A few positive anomalies, i.e. the observed nitrate was higher than prediction, could be caused by solar heating or by mixing of nitrate-devoid surface waters which were warmer than the threshold temperature. On the other hand, the negative anomalies were more common and indicates nitrate uptake. During September-November 1990 and May 1991, the observed values were lower than the prediction by about $0.3 \mu \mathrm{M}$ on the average. Most notably, a high negative anomaly, up to about $1.5 \mu \mathrm{M}$, occurred in November 1990 , suggesting high nitrate uptake [Fig. 9(d)]. The maximum nitrate deficit corresponded to a chlorophyll $a$ concentration of $3 \mathrm{mg} \mathrm{m}^{-3}$ as calculated from in situ fluorometer data (Gong et al., 1994). The mean chlorophyll $a$ concentration in surface waters with no nitrate deficit was about $0.6 \mathrm{mg} \mathrm{m}^{-3}$. Chen (1992) reported chlorophyll $a$ concentration lower than 0.5 $\mathrm{mg} \mathrm{m}^{-3}$ in shelf water in August 1990, when the surface water was all devoid of nitrate. Therefore, the nitrate deficit derived from model calculation is a useful indicator of nitrate uptake and phytoplankton growth, which warrants further investigation. Similar application has been used in a study of primary and new production (e.g. Yoder et al., 1985; Dugdale et al., 1989).

\section{Nutrient supply from Kuroshio to the shelf}

The foregoing discussion clearly indicates the wide spread presence of the upwelled Kuroshio water as a nutrient source to the shelf water of the southern East China Sea. The riverine input of nutrients which shows up in the less saline coastal water with $S<34$ psu is scarcely seen in the mid- and outer shelf. The benthic regeneration of nutrients is insignificant in this shelf area where the sediments are relic sand and the organic carbon content is very low $(<0.3 \%)$ (Lin et al., 1992b). Therefore, the upwelled water is the dominant source of nutrients in the mid- and outer shelf of the southern East China Sea. This is very similar to the nutrient supply in the southeastern U.S. continental shelf or the South Atlantic Bight. However, the provision of the upwelled water in this study area appears to be stronger and more persistent than in the South Atlantic Bight. The Kuroshio upwelling is a year-round phenomenon (Liu et al., 1992b), which is estimated to have a transport of about $0.2 \mathrm{~Sv}$ in an area of $50 \mathrm{~km} \times 50 \mathrm{~km}$ (Liu et al., 1992b). This upwelling is facilitated by the counter current at the continental slope off northeastern Taiwan where Kuroshio impinges onto the continental shelf (Chuang et al., 1993). In the South Atlantic Bight, topographically enhanced upwelling also occurs but the intensity seems less striking 
than the Kuroshio upwelling (Pietrafesa et al., 1985). Atkinson (1985) reported that nutrients are supplied from upwelling of the Gulf Stream water in association with frontal eddies which are episodic in nature (e.g. Lee et al., 1981; Lee and Atkinson, 1983).

In conclusion, this study provides unequivocal evidence to the notion that the upwelled Kuroshio water is a persistent and important source of nutrients to the southern East China Sea shelf. The constancy of the nutrient-laden end member enables the prediction of nitrate concentration in the water of the mid- and outer shelf with a simple mixing model.

Acknowledgements-We would like to thank the captain and the crew of the R.V. Ocean Research I for their assistance during field investigations. Mr Yih-Chung Li, Wen-Rong Yang and Yun-Ho Wen for their kind assistance with the experiments. Meteorological data provided by Central Weather Bureau and satellite SST images provided by Taiwan Fisheries Research Institute are also appreciated. We are grateful for the comments and suggestions from R. N. Sambrotto, George, T. F. Wong and an anonymous reviewer. This study was supported by grants from National Science Council of the Republic of China, NSC-82-0209-M-019-016-K, NSC-83-0209-M-019-003-K (GCG) and NSC-82-0209-M-001-070-K (KKL).

\section{REFERENCES}

Anon (1990) Fisheries yearbook-Taiwan area. Taiwan Fisheries Bureau, Department of Agriculture and Forestry, Provincial Government of Taiwan, $652 \mathrm{pp}$.

Atkinson L. P. (1985) Hydrography and nutrients of the southeastern U.S. continental shelf. In: Coastal and Estuarine Sciences Vol. 2. Oceanography of the southeastern U.S. continental shelf. L. P. Atkinson, D. W. Menzel and K. A. Bush, editors, pp. 77-92.

Brink K. H., B. H. Jones, J. C. Van Leer, C. N. K. Mooers, M. R. Stevenson, R. C. Dugdale and G. W. Heburn (1981) Physical and biological structure and variability in an upwelling center off Peru near $15^{\circ} \mathrm{S}$ during March, 1977. In: Coastal upwelling, coastal and estuarine science, Vol. 1, F. A. Richards, editor, pp. 473496, AGU, Washington, D.C.

Chao S.-Y. (1991) Circulation of the East China Sea, a numerical study. Journal of the Oceanological Society of Japan, 46, 273-295.

Chen Y. L. (1992) Summer phytoplankton community structure in the Kuroshio current-induced upwelling northeast of Taiwan. Terrestrial, Atmospheric and Oceanic Science, 3, 305-320.

Chern C.-S. and J. Wang (1989) On the water masses at northern offshore area of Taiwan. Acta Oceanographica Taiwanica, 22, 14-32.

Chern C.-S. and J. Wang (1990) On the mixing of waters at a northern offshore area of Taiwan. Terrestrial, Atmospheric and Oceanic Sciences, 1, 297-306.

Chiu T.-S. (1991) Variation of ichthyoplankton density across the Kuroshio Edge Exchange Area with implications as to the water masses. Terrestrial, Atmospheric and Oceanic Sciences, 2, 147-162.

Chuang W.-S., H.-W. Li, T.-Y. Tang and C.-K. Wu (1993) Observations of the countercurrent on the inshore side of the Kuroshio northeast of Taiwan. Journal of Oceanography, 49(5), 1993.

Dugdale R. C., A. Morel, A. Bricaud and F. P. Wilkerson (1989) Modeling new production in upwelling centers: A case study of modeling new production from remotely sensed temperature and color. Journal of Geophysical Research, 94, 18,119-18,132.

Gardner W. S., D. S. Wynne and W. M. Dunstan (1976) Simplified procedure for the manual analysis of nitrate in seawater. Marine Chemistry, 4, 393-396.

Gong G.-C. (1992) Chemical hydrography of the Kuroshio front in the sea northeast of Taiwan. Ph.D. dissertation, Institute of Oceanography, National Taiwan University, 204 pp.

Gong G.-C., W.-J. Yang and K.-K. Liu (1994) Kuroshio Edge Exchange Processes, Chlorophyll a fluorescence sections (I), August 1990-July 1991, R/V Ocean Research I. Regional Instrument Center, Data Report, National Science Council, Taipei.

JGOFS (1992) Joint Global Ocean Flux Study Implementation Plan. JGOFS Report No. 9, Scientific Committee on Oceanic Research, International Council of Scientific Union.

Jones B. H., K. H. Brink, R. C. Dugdale, D. W. Stuart, J. C. Van Leer, D. Blasco and J. C. Kelley (1983) Observations of a persistent upwelling center off Point Conception, California. In: Coastal upwelling, Part $A$, E. Suess and J. Thiede, editors, pp. 37-60, Plenum Press, New York. 
Lee T. N., L. P. Atkinson and R. Legeckis (1981) Observations of a Gulf Stream frontal eddy on the Georgia continental shelf, April 1977. Deep Sea Research, 28, 347-378.

Lee T. N. and L. P. Atkinson (1983) Low frequency current and temperature variability from Gulf Stream frontal eddies and atmospheric forcing along the southeastern U.S. outer continental shelf. Journal of Geophysical Research, 88, 4541-4567.

Lin C.-Y., C.-Z. Shyu and W.-H. Shih (1992a) The Kuroshio fronts and cold eddies off northeastern Taiwan observed by NOAA-AVHRR imageries. Terrestrial, Atmospheric and Oceanic Sciences, 3, 225-242.

Lin S., K.-K. Liu, M. P. Chen, P. Chen and F. Y. Chang (1992b) Distribution of organic carbon in the KEEP area continental margin sediments. Terrestrial, Atmospheric and Oceanic Sciences, 3, 365-378.

Liu K.-K., S.-C. Pai and C.-T. Liu (1988) Temperature-nutrient relationships in the Kuroshio and adjacent waters near Taiwan. Acta Oceanographica Taiwanica, 21, 1-17.

Liu K.-K., G.-C. Gong, S. Lin, C.-Z. Shyu, S.-C. Pai, C. L. Wei and S.-Y. Chao (1992a) Response of Kuroshio upwelling to the onset of northeast monsoon in the sea north of Taiwan: observations and a numerical simulation. Journal of Geophysical Research, 97, 12,511-12,526.

Liu K.-K., G.-C. Gong, S. Lin, C.-Z. Shyu, C.-Y. Yang, C.-L. Wei, S.-C. Pai and C.-K. Wu (1992b) The yearround upwelling at the shelf break near the northern tip of Taiwan as evidenced by chemical hydrography. Terrestrial, Atmospheric and Oceanic Sciences, 3, 234-276.

Miao Y. and H. Yu (1990) Spatial and temporal variation of water mass mixing characteristic in the East China Sea. Proceedings, Japan-China Joint Symposium of the Cooperative on the Kuroshio, Science and Technology Agency, Tokyo, 1990, pp. 157-169.

Morris A. W. and J. P. Riley (1963) The determination of nitrate in seawater. Analytica Chimica Acta, 29, 272279.

Pai S.-C., C.-C. Yang and J. P. Riley (1990) Formation kinetics of the pink azo dye in the determination of nitrite in natural waters. Analytica Chimica Acta, 232, 345-349.

Pietrafesa L. J., G. S. Janowitz and P. A. Wittman (1985) Physical oceanographic processes in the Carolina Capes. Coastal and Estuarine Sciences 2. Oceanography of the southeastern U.S. continental shelf, L. P. Atkinson, D. W. Menzel and K. A. Bush, editors, pp. 23-32.

Sathyendranath S., T. Platt, E. P. W. Horne, W. G. Harrison, O. Ulloa, R. Outerbridge and N. Hoepffner (1991) Estimation of new production in the ocean by compound remote sensing. Nature, 353, 129-133.

Strickland J. D. H. and T. R. Parsons (1972) A practical handbook of seawater analysis. Fisheries Research Board of Canada, Ottawa, Canada, $310 \mathrm{pp}$.

Sun X. (1987) Analysis of the surface path of the Kuroshio in the East China Sea (in Chinese with English abstract). Essays on the investigation of Kuroshio, by X. Sun, editor, Ocean Press, Beijing, pp. 1-14.

Walsh J. J. (1991) Importance of continental margins in the marine biogeochemical cycling of carbon and nitrogen. Nature, 350, 53-55.

Wong G. T.-F., S.-C. Pai, C.-T. Liu and C.-T. A. Chen (1989) Chemical hydrography across the East China Sea-Kuroshio frontal region, northeast of Taiwan. Acta Oceanographica Taiwanica, 23, 1-18.

Wong G. T-F., S.-C. Pai, K.-K. Liu, C.-T. Liu and C.-T. A. Chen (1991) Variability of the chemical hydrography at the frontal region between the East China Sea and the Kuroshio northeast of Taiwan. Estuarine and Coastal Shelf Science, 33, 105-120.

Yoder J. A., L. P. Atkinson, S. S. Bishop, J. O. Blanton, T. N. Lee and L. J. Pietrafesa (1985) Phytoplankton dynamics within Gulf Stream intrusions on the southeastern United States continental shelf during summer 1981. Continental Shelf Research, 4, 611-635. 